\title{
A Very Rare Case of Mass-Like Mesenteric Fat Necrosis in a Patient with Antiphospholipid Syndrome
}

\author{
Ana Luísa Lourenço $^{a}$ João Lopes Dias ${ }^{a}$ Joana Marques ${ }^{b}$ Vera Bernardino $^{c}$ \\ ${ }^{a}$ Radiology Department, Centro Hospitalar e Universitário de Lisboa Central, Lisbon, Portugal; ${ }^{b}$ Nephrology \\ Department, Centro Hospitalar e Universitário de Lisboa Central, Lisbon, Portugal; ' Internal Medicine Department, \\ Centro Hospitalar e Universitário de Lisboa Central, Lisbon, Portugal
}

\section{Keywords}

Intra-abdominal steatonecrosis · Panniculitis .

Antiphospholipid syndrome

\section{Abstract}

Introduction: Intra-abdominal fat is a metabolically active tissue that can undergo necrosis due to torsion, infarction, or trauma. Despite being asymptomatic in most cases, fat necrosis or steatonecrosis can cause abdominal pain. Case Presentation: This article describes the case of a male patient admitted to the emergency department with diffuse abdominal pain for the past month. The patient had a past medical history of antiphospholipid syndrome with multiple venous thromboembolic events and one episode of lower limb vasculitis, currently under anticoagulation treatment. Imaging studies with computed tomography and magnetic resonance revealed a mesenteric mass-like lesion adjacent to the ileal bowel loops. The patient underwent surgical resection, and the microscopic analysis revealed extensive organizing fat necrosis with reactive panniculitis and hemorrhage. Discussion and Conclusion: This article describes a rare case of a mesenteric mass-like encapsulated fat necrosis in a patient with antiphospholipid syndrome, with very atypical location and imaging features.

(c) 2020 Sociedade Portuguesa de Gastrenterologia Published by S. Karger AG, Basel

\section{Esteatonecrose mesentérica encapsulada num doente com síndrome antifosfolipídico: um caso raro}

\author{
Palavras Chave \\ Esteatonecrose intra-abdominal · Paniculite · Síndrome \\ antifosfolipídico
}

\section{Resumo \\ Introdução: A gordura intra-abdominal, sendo um tecido metabolicamente ativo, pode sofrer necrose por torsão, enfarte ou trauma. Na maioria dos casos a esteatonecrose é assintomática podendo, no entanto, cursar com dor ab- dominal. Apresentação do Caso: Este artigo descreve o caso de um doente do sexo masculino que recorreu ao}

karger@karger.com www.karger.com/pjg

Karger $\stackrel{\text { ' }}{5}$

BOPEN ACCESS
(C) 2020 Sociedade Portuguesa de Gastrenterologia Published by S. Karger AG, Basel

This article is licensed under the Creative Commons AttributionNonCommercial-NoDerivatives 4.0 International License (CC BY NC-ND) (http://www.karger.com/Services/OpenAccessLicense). Usage and distribution for commercial purposes as well as any distribution of modified material requires written permission.
Ana Luísa Lourenço

Radiology Department, Centro Hospitalar e Universitário de

Lisboa Central, Alameda de Santo António dos Capuchos

PT-1169-051 Lisbon (Portugal)

ana.lmlourenco@gmail.com 
serviço de urgência por dor abdominal generalizada com um mês de evolução. $O$ doente tinha síndrome antifosfolipídico e antecedentes de eventos trombóticos e vasculite dos membros inferiores, atualmente sob terapêutica anticoagulante. Estudos imagiológicos por tomografia computorizada e ressonância magnética revelaram uma massa mesentérica adjacente a ansas de íleon. $O$ doente foi submetido a uma resseção cirúrgica e a análise microscópica demonstrou extensas áreas de esteatonecrose em organização, com paniculite reativa e hemorragia. Discussão e Conclusão: Este artigo descreve um caso raro de esteatonecrose mesentérica encapsulada num doente com síndrome antifosfolipídico, com localização e apresentação imagiológica muito atípicas.

C 2020 Sociedade Portuguesa de Gastrenterologia Published by S. Karger AG, Basel

\section{Introduction}

Fat tissue, being metabolically active, can undergo ischemic transformation, sometimes resulting in a masslike encapsulated fat necrosis (EFN). EFN was first described in the breast, but it can occur anywhere, including in the intraperitoneal space. The pathophysiology behind this entity is not well understood, but trauma and ischemia are the most accepted causes leading to adipose tissue lobule infarction. $[1,2]$ Greater omentum or epiploic appendage torsion and infarction are the most common types of EFN [3].

Antiphospholipid syndrome (APS) is characterized by a combination of anti-phospholipid antibodies and recurrent vascular thrombosis $[4,5]$. Vascular thrombotic events include thrombotic microangiopathy and may compromise capillaries, arterioles, or venules of different organs and tissues, eventually leading to ischemia and organ failure [2].

\section{Case Report and Case Presentation}

A 42-year-old male patient was admitted to the emergency department with abdominal pain for the past month. Other symptoms included fever and weight loss, and changes in bowel habits were denied. There was no past history of trauma or intra-abdominal inflammatory disease such as pancreatitis. The patient had APS with multiple venous thromboembolic events. This included episodes of deep vein thrombosis at 16 and 18 years of age, pulmonary embolisms at 23 and 41 years, and an ischemic stroke at 38 years affecting the left vertebral artery. There was also an episode of APS-associated lower limb vasculitis, currently resolved. He was treated with warfarin, with regular monitoring of his in-
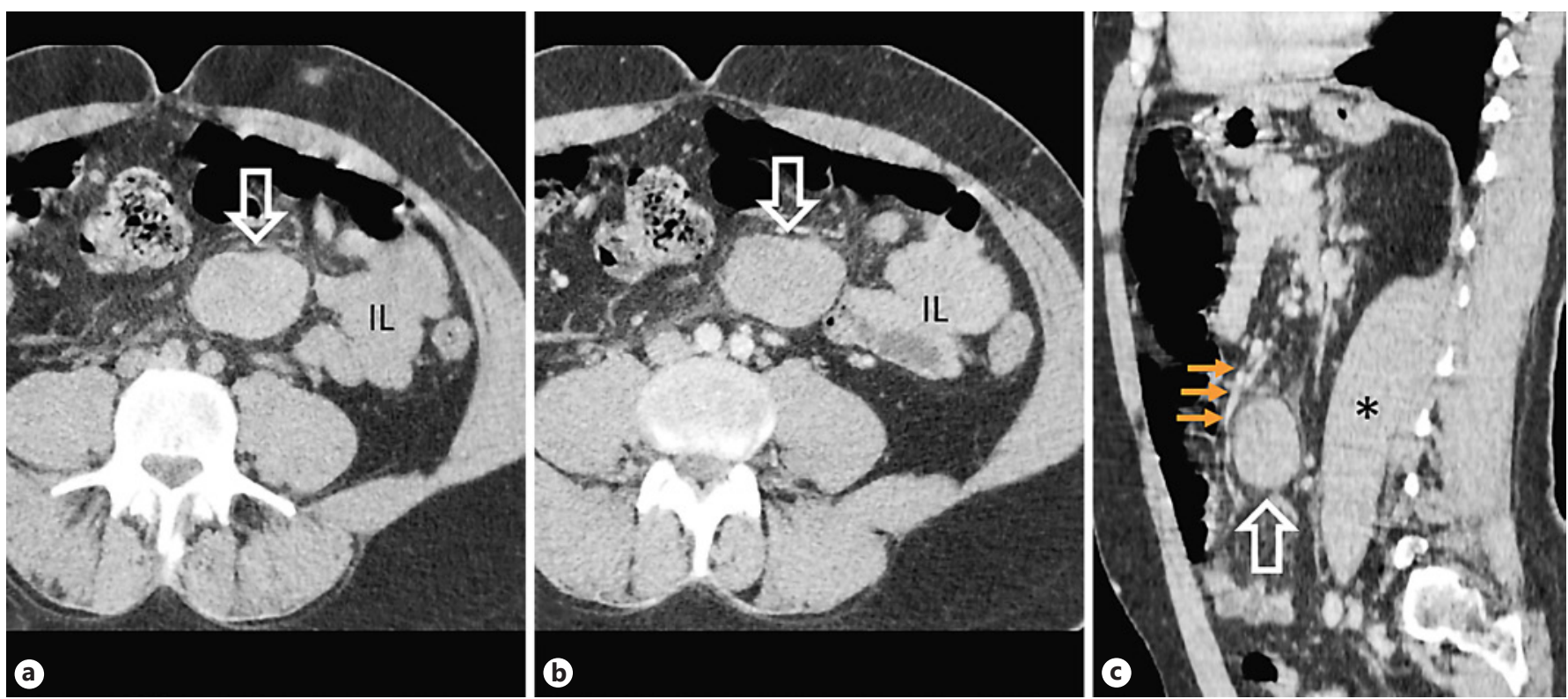

Fig. 1. Non-enhanced (a) and post-contrast abdominal CT scans (b) showing a well-defined, non-calcified mesenteric mass (arrows), with approximately 50 Hounsfield units, with adjacent fat stranding. No significant contrast uptake and no bowel obstruction are noticed. On the sagittal post-contrast CT scan (c) the mesenteric mass (arrow) is between and displacing mesenteric vessels (small arrows). IL, ileum bowel loops; asterisk, left psoas muscle. 
ternational normalized ratio, with a target between 3 and 4. Physical examination revealed diffuse abdominal tenderness, slightly more pronounced on the left upper and lower quadrants, without peritonism and palpable masses. Blood results were unremarkable. The patient underwent a contrast-enhanced abdomen and pelvis computed tomography (CT) scan at another institution a few days prior to this presentation (Fig. 1). The scan revealed a left-sided mass adjacent to the ileal bowel loops, displacing the mesenteric vessels and measuring $5 \times 3.7 \mathrm{~cm}$ (axial plane). The ileal bowel loops were displaced; however, no bowel obstruction was reported. The mass was heterogeneous, non-calcified, with lobulated margins, mostly isodense compared to muscle tissue on unenhanced images, without manifest enhancement on post-contrast acquisitions (arterial and portal-venous phases). Small regional lymph nodes and a moderate amount of peritoneal free fluid were also recognized. A gadolinium-enhanced magnetic resonance (MR) of the abdomen and pelvis was performed at our institution (Fig. 2) for a more accurate characterization. It confirmed the presence of an encapsulated mesenteric mass, slightly greater in size compared to the previous CT, with $5 \times 4 \mathrm{~cm}$ (axial plane). It was isointense compared to the muscle tissue on T1weighted images and mostly hypointense on T2-weighted images, with small hyperintense internal areas. The mass had no signs of intra- or extracellular fat components, and no restricted diffusion was noticed. Intravenous administration of gadolinium showed no significant contrast uptake. Reactive findings with progressive contrast enhancement of the adjacent fat tissue and peritoneal layers were seen.

Taking into account these clinical and radiological findings, the described mesenteric mass could represent a desmoid tumor, mainly due to the fact that it did not demonstrate significant enhancement after intravenous contrast administration. A mass-like encapsulated steatonecrosis was also suspected, considering the absence of post-contrast enhancement and the patient's medical history of APS with multiple venous thromboembolic events. However, fat imaging signs were absent, both on CT and MR, and the mesenteric root is an uncommon location for steatonecrosis. Surgical excision of the mesenteric mass together with two adherent distal ileum segments was performed.

Macroscopically, the mass was encapsulated, with a smooth outline and elastic shape, in the subserosa of the ileum. Microscopic histological analysis (Fig. 3) showed the mesentery with areas of organizing panniculitis, steatonecrosis, and hemorrhage, surrounded by an inflammatory infiltrate with abundant lymphocytes and histiocytes.
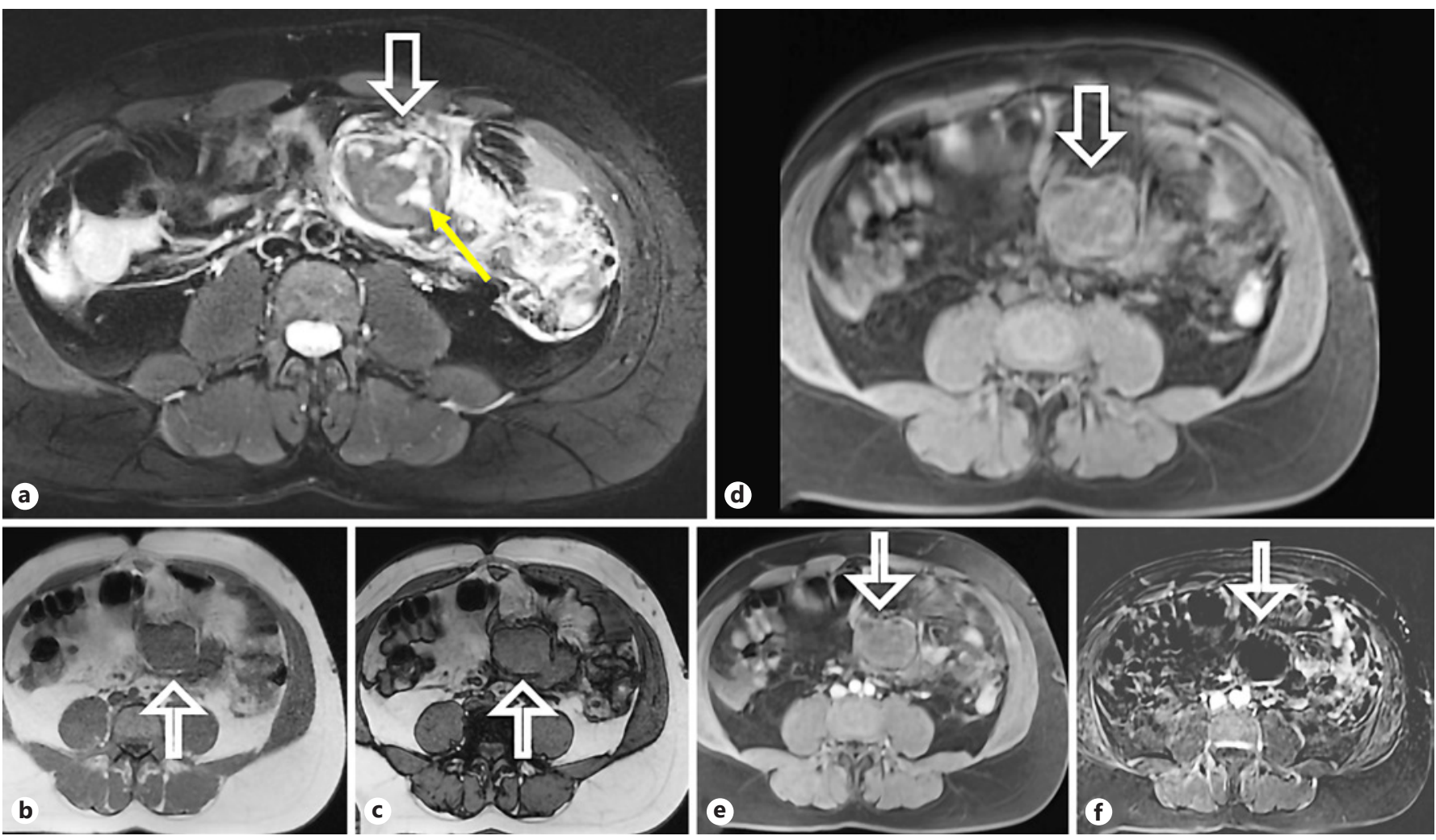

Fig. 2. MR scans (a-f) showing the mesenteric mass (arrows), with internal areas of edema on a T2-weighted image (yellow arrow in a). The mass shows no signs of intracellular fat content on the in-phase (b) and out-of-phase (c) T1-weighted images. No extracellular fat is seen on the fat-suppressed T1-weighted image (d). Fat-suppressed T1-weighted after gadolinium administration (e) and its respective subtraction sequence (f) show no contrast uptake.

Mass-Like Mesenteric Fat Necrosis in a Patient with Antiphospholipid Syndrome
GE Port J Gastroenterol 2021;28:139-143 DOI: $10.1159 / 000507939$ 

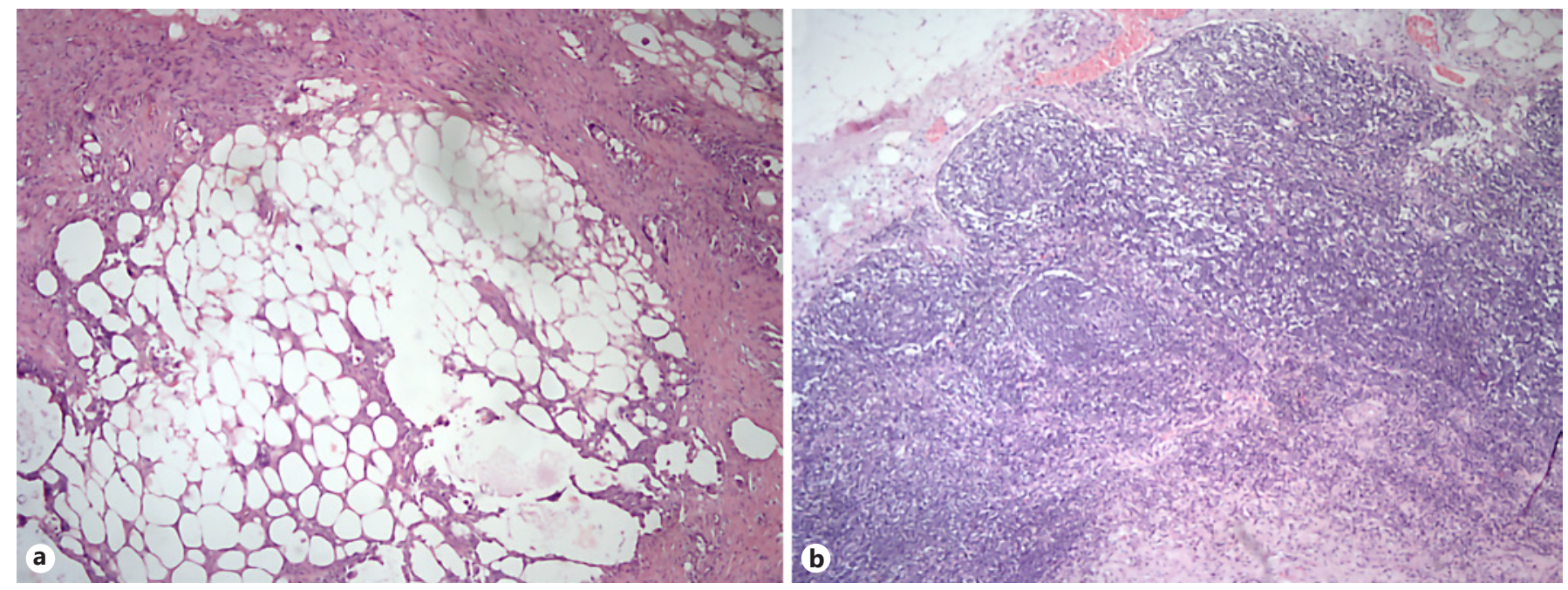

Fig. 3. Microscopic histological analysis. a Mesentery with areas of steatonecrosis and inflammatory cell infiltrate (H\&E. $\times 50)$. b Area of necrosis and hemorrhage surrounded by an inflammatory infiltrate with abundant lymphocytes and histiocytes $(\mathrm{H} \& \mathrm{E} . \times 50)$.

\section{Discussion and Conclusion}

Intraperitoneal focal fat infarction includes acute abdominal clinical conditions in which focal fatty tissue necrosis represents the common pathological factor. In clinical practice, most cases of intraperitoneal focal fat infarction concern torsion and/or infarction of the greater omentum or epiploic appendages. To our knowledge there are very few cases of mesenteric EFN described in literature [3].

Despite the location, the most common imaging feature of EFN on CT and MR scans relates to its fat content: CT scan shows low-density internal areas, and MR usually shows signs of intra- and/or extracellular internal fat content (signal drop on fat-suppressed T1 - or T2-weighted images and also on the out-of-phase T1-weighted images). EFN may display a surrounding capsule, which can enhance after intravenous contrast administration. The infarction's microscopic appearance changes over time: firstly, hemorrhagic infarction with fat necrosis is appreciated, followed by infiltration by lymphocytes, histiocytes and fibroblasts, the latter leading to fibrosis and scar tissue formation $[2,3,5]$.

This case report describes a mesenteric mass-like fat necrosis in a patient with APS, without fat content imaging signs, which were probably obscured by the presence of extensive panniculitis and inflammatory cells, as demonstrated above in the microscopic analysis. Patients with APS have a higher incidence of vascular and microangio- pathic thrombosis, which we considered to be the main cause for EFN formation described in this case report. Moreover, some authors state a possible association, though rare, between APS and vascular inflammation [6, 7]. Since the patient had a previous lower limb vasculitis episode, we think that reactive inflammatory vasculitis could be an additional cause for the pathophysiology of fat necrosis.

Fat necrosis can cause abdominal pain, which can clinically mimic an acute abdomen. From a radiological point of view, if fat content was evident, liposarcoma would be the most important differential diagnosis. In our case, desmoid tumor was also considered, although lower to intermediate signal intensity would be expected on T1weighted images. Desmoid tumor's signal intensity is variable on both $\mathrm{T} 2$-weighted and after gadolinium administration images, depending on the histological component. The ENF natural temporal evolution is size reduction $[2,3,8]$.

In conclusion, the purpose of this article is to describe a rare case of mesenteric mass-like EFN, with an uncommon association with APS and with an atypical imaging presentation due to the absence of fat content features.

\section{Acknowledgement}

The authors would like to thank Dr. Margarida Varela, Pathology Department, Centro Hospitalar e Universitário de Lisboa Central, for slide review and helpful discussion. 


\section{Statement of Ethics}

Written informed consent was obtained from the patient for the publication of this case report and accompanying images.

\section{Disclosure Statement}

The authors have no conflicts of interest to declare.

\section{Funding Sources}

This research received no specific grant from any funding agency in the public, commercial, or not-for-profit sectors.

\section{Author Contributions}

A.L.L conceived the manuscript, which was drafted together with J.L.D. J.M. and V.B participated in the review process. All authors critically revised the manuscript and provided final approval of the version to be submitted.

\section{References}

1 Kamaya A, Federle MP, Desser TS. Imaging manifestations of abdominal fat necrosis and its mimics. Radiographics. 2011 Nov-Dec; 31(7):2021-34

2 De Kock I, Delrue L. Encapsulated Mesenteric Fat Necrosis. J Belg Soc Radiol. 2016 Mar; 100(1):53.

3 Coulier B. Contribution of US and CT for diagnosis of intraperitoneal focal fat infarction (IFFI): a pictorial review. JBR-BTR. 2010 JulAug;93(4):171-85.
4 Johnsen SJ, Valborgland T, Gudlaugsson E, Bostad L, Omdal R. Thrombotic microangiopathy and the antiphospholipid syndrome. Lupus. 2010 Nov;19(13):1569-72.

5 Garcia D, Erkan D. Diagnosis and Management of the Antiphospholipid Syndrome. N Engl J Med. 2018 May;378(21):2010-21.

6 Lally L, Sammaritano LR. Vasculitis in antiphospholipid syndrome. Rheum Dis Clin North Am. 2015;41(1):109-23.
7 Lie JT. Vasculopathy of the antiphospholipid syndromes revisited: thrombosis is the culprit and vasculitis the consort. Lupus. 1996 Oct; 5(5):368-71.

8 Braschi-Amirfarzan M, Keraliya AR, Krajewski KM, Tirumani SH, Shinagare AB, Hornick $\mathrm{JL}$, et al. Role of Imaging in Management of Desmoid-type Fibromatosis: A Primer for Radiologists. Radiographics. 2016 May-Jun; 36(3):767-82. 